\title{
Challenging norms of gender and language
}

\author{
Pocholo Umbal and Nadia Takhtaganova \\ University of Toronto
}

\section{Introduction}

In recent years, we have seen a paradigm shift in the scholarship of language, gender, and sexuality. Greater recognition of gender diversity has challenged traditional models of gender identity that assumed static and binary categories, which were largely taken for granted in early socio(cultural) linguistic work. At times when gender-diverse communities were considered, it was often for how they stood as marked exceptions or elaborations on existing theories, rather than for the innovative, semiotically rich practices that they embody, which, in turn, characterize them. Recent work has provided theoretical frameworks that engage with the fluidity of gender identities more rigorously (e.g., Bucholtz \& Hall 2005; Zimman 2020). Much of these expansive discussions of gender identity have taken place in the last decade: for example, we have seen increasing attention paid to the use of non-binary pronouns (Conrod 2020; Konnelly \& Cowper 2020) and variation in grammatical gender (Abe 2019; Bershtling 2014; Borba \& Ostermann 2007). We have seen studies of how transgender speakers modulate phonetic features in identity construction (Zimman 2012), how transgender communities navigate discursive expectations of normative forms of embodiment (Jones 2019; Miller 2019), and how (trans)gender identities intersect with other axes such as racialization (Davis 2014; Steele forthcoming). Moreover, trans linguistic (Zimman 2020) scholarship has demonstrated the enormous impact of language on trans people's quality of life: previous studies have demonstrated the ways in which language is central to affirmative health care access for non-binary individuals (Bouman et al. 2017; Zieger 2016), and how the language of gender in the legal system constrains or excludes possibilities for trans existence (McDonald, Byrne \& Dickson 2017; Tao 2017).

In this special issue of Toronto Working Papers in Linguistics, we engage in this productive and growing conversation by bringing together ongoing work on gender-inclusive language as well as linguistic practices among trans and non-binary communities. Each of these papers offers a unique perspective on the ever-diversifying nuances of language and the societies in which it is used. Together, they challenge established norms of language use and research practices.

\section{The papers}

In the first paper, Gabrielle Dumais reframes the investigation of non-binary discourse in French to urban Quebec. In particular, she focuses on the contrast between prescribed neologisms by the Office québécois de la langue française and everyday, informal discourse. In her discussion, she highlights a preference for gender avoidance strategies in the inevitable presence of morphological gender in French, including the resistance of the third person inflectional paradigm (most commonly marked for gender cross-linguistically) toward gender neutralization.

Still firmly situated in French-speaking Canada, the second paper, by Yarubi Diaz, discusses the typographic practices related to inclusive French on Twitter. She observes that, unlike spoken informal Québec French, informal written Canadian French appears to be consistent with the recommendations of the Office québécois de la langue française, although numerous agreement strategies can be employed both in tandem and separately in different tweets. She highlights that the variety of available alternatives in this writing system is what ultimately characterizes inclusive Canadian French.

In the third paper, Jordan Tudisco takes us across the pond to non-binary discourse in the French Metropolitan, where written language especially faces immense social pressure engendered by the stylistic prescriptions of l'Académie française. Through an examination of the linguistic practices of trans users on 
two online forums, they highlight three salient strategies trans and non-binary individuals use to reclaim a sense of linguistic authority and self-determination.

The fourth paper, by Archie Crowley, discuses the experiences of transmasculine individuals undergoing testosterone therapy. Crowley focuses on two ethnographic interviews with transmasculine individuals, and, by drawing on the construct of apperception, they investigate the ways in which the sensory experiences that coincide with changes to their voice are connected to various qualia of the voice. This relationship, in turn, is linked to a broader understanding of gender and masculinity. Further, they show us how although the voice becomes a crucial part of being gendered as men in social spaces, this positive shift nevertheless creates tension between identity and newfound privilege and power.

In the fifth paper, Lex Konnelly provides a more nuanced understanding of how transgender people navigate a transmedicalist model of transgender care. Through an analysis of non-binary healthcare narratives centered around descriptions of gender dysphoria in the consultation room, they explore how their participant-collaborators use discursive strategies as forms of intervention - to convey an "approximate truth" including sufficient information for accessing gender-affirming care. Konnelly argues that these practices reflect critical thirding, an "other than" choice that goes beyond the dichotomous view of transnormativity or resistance.

Finally, LeAnn Brown's paper pushes us to reflect about how we can engage in research in ways that affirm and empower both researchers and research collaborators. In particular, she invites researchers to integrate pragmatism and mixed methods approaches in research with non-binary communities as well as center non-binary voices and their experiences. She highlights three aspects of non-binary populations that demonstrate the utility of a pragmatic and mixed methods framework for sociophonetic work; and in doing so, brings us closer to research that is transformative.

\section{Conclusion}

The body of work presented here highlights linguistic developments towards gender-inclusive language, as well as underscores the importance of linguistic agency for trans and non-binary individuals. Further, by looking at their linguistic practices, we gain a more nuanced insight into the construction and performance of a myriad of gender identities. We hope that this issue contributes to the growing body of work on gender diversity, and that it sparks a productive conversation on how we can conduct research with trans and nonbinary communities in empowering and affirming ways.

Acknowledgements. We sincerely thank the authors for their careful work. We also thank the anonymous reviewers and the TWPL editorial team for their efforts. Special thanks to Lex Konnelly, Lisa Schlegl, Lauren Bigelow, Nathan Sanders, and Naomi Nagy for their support and feedback.

\section{References}

Abe, Hideko. 2019. Indexicality of grammar: The case of Japanese transgender speakers. In The Oxford handbook of language and sexuality, ed. Kira Hall and Rusty Barrett. Oxford: Oxford University Press. doi: 10.1093/oxfordhb/9780190212926.013.16

Bershtling, Orit. 2014. "Speech creates a kind of commitment": Queering Hebrew. In Queer excursions: Retheorizing binaries in language, gender, and sexuality, ed. Lal Zimman, Jenny L. Davis and Joshua Raclaw. New York: Oxford University Press. doi: 10.1093/acprof:oso/9780199937295.003.0003

Borba, Rodrigo, and Cristina Ostermann. 2017. Do bodies matter? Travestis' embodiment of (trans)gender identity through the manipulation of the Brazilian Portuguese grammatical gender system. Gender and Language 1(1): 131-147. 
Bouman, Walter Pierre, Amets Suess Schwend, Joz Motmans, Adam Smiley, Joshua D. Safer, Madeline B. Deutsch, Noah J. Adams, and Sam Winter. 2017. Language and trans health. International Journal of Transgenderism 18(1): 1-6.

Bucholtz, Mary, and Kira Hall. 2005. Identity and interaction: A sociocultural linguistic approach. Discourse Studies 7(4-5): 585-614.

Conrod, Kirby. 2020. Pronouns and gender in language. In The Oxford handbook of language and sexuality, ed. Kira Hall and Rusty Barrett. Oxford: Oxford University Press. doi: 10.1093/oxfordhb/9780190212926.013.63

Jones, Lucy. 2019. Discourses of transnormativity in vloggers' identity construction. International Journal of the Sociology of Language 256: 85-101.

McDonald, Elisabeth, Jack Byrne, and Sandra Dickson. 2017. The significance of naming harm for trans women: Defining rape in Aotearoa New Zealand. In Representing trans: Linguistic, legal, and everyday perspectives, ed. Evan Hazenberg and Miriam Meyerhoff. Wellington, New Zealand: Victoria University Press.

Miller, Jordan F. 2019. YouTube as a site of counternarratives to transnormativity. Journal of Homosexuality 66(6): 815-837.

Steele, Ariana. Forthcoming. Enacting new worlds of gender: Non-binary speakers, racialized gender, and anti-Colonialism. In The Oxford handbook of language and sexuality, ed. Kira Hall and Rusty Barrett. Oxford: Oxford University Press.

Tao, Kimberly. 2017. The construction of transgender identities through legal and self perspectives. In Representing trans: Linguistic, legal, and everyday perspectives, ed. Evan Hazenberg and Miriam Meyerhoff, 77-103. Wellington, New Zealand: Victoria University Press.

Zieger, Avery E. F. 2016. Transgender identity and ethics of care: Narrative analysis of transgender identities and experiences of care in Saskatchewan. Master's thesis, University of Saskatchewan.

Zimman, Lal. 2012. Voices in transition: Testosterone, transmasculinity, and the gendered voice among female-to-male transgender people. Doctoral dissertation, University of Colorado.

Zimman, Lal. 2020. Transgender language, transgender moment: Toward a trans linguistics. In The Oxford handbook of language and sexuality, ed. Kira Hall and Rusty Barrett (eds). Oxford: Oxford University Press. doi: 10.1093/oxfordhb/9780190212926.013.45 